\title{
Prólogo à História da Psicologia
}

\author{
José Antônio Damásio Abib ${ }^{1}$ \\ Universidade Federal de São Carlos
}

\begin{abstract}
RESUMO - O texto da história da psicologia é um intertexto e o método de pesquisa dessa disciplina dirige-se para a elucidação desse intertexto. O historiador da psicologia trata com textos de psicólogos, filósofos e historiadores das culturas e das idéias. Começa investigando um texto de um psicólogo e aprofunda e amplia seu exame com o estudo de textos filosóficos e históricos que freqüentemente permanecem silenciosos no texto do psicólogo. Seguindo esse método, narra as reconstruções racionais (as analogias conceituais entre o texto do psicólogo e o pré-texto filosófico) e as revoluções psicológicas (ao inserir as reconstruções racionais nos seus contextos cultural e intelectual) que constituem o memorial da psicologia. Os casos Wilhelm Wundt por Kurt Danziger, e Edward C. Tolman por Laurence Smith são apresentados para ilustrar concretamente nossa caracterização da história da psicologia; e, também, para mostrar como escorregos e omissões intertextuais conduzem a equívocos e simplificações surpreendentes, que não poupam os melhores historiadores.
\end{abstract}

Palavras-chave: pesquisa intertextual; reconstruções racionais; revoluções psicológicas; Kurt Danziger; Laurence Smith.

\section{Prologue to the History of Psychology}

\begin{abstract}
In this essay, it is suggested that the text of the history of psychology is an intertext, and the objective of the method of research of this discipline is the elucidation of this intertext. The historian of psychology deals with texts of psychologists, philosophers and historians of cultures and ideas. He begins by investigating a text of a psychologist, and deepens and widens his analysis with the study of philosophical texts and historical texts which frequently remain silent in the text of the psychologist. Following this method, the historian of psychology narrates the rational reconstructions (the conceptual analogies between the text of the psychologist and the philosophical pre-text) and the revolutions in psychology (by situating the rational reconstructions in their cultural and intellectual contexts) which constitute the memorial of psychology. Kurt Danziger's treatment of Wilhelm Wundt, and Laurence Smith's treatment of Edward C. Tolman are given as examples of our characterization of the history of psychology; and of how intertextual slips and oversights lead to surprising mistakes and simplifications, made by even the best of historians.
\end{abstract}

Key words: intertextual research; rational reconstructions; psychological revolutions; Kurt Danziger; Laurence Smith.

Freqüentemente o primeiro contato com história da psicologia é com o texto de historiador da disciplina. Tomado mais como objeto de instrução doutrinária do que de recepção crítica, suas interpretações são simplesmente reproduzidas, sem que haja uma indagação, sequer preliminar, sobre o modo como o texto foi construído. Se, por outro lado, se tomasse o texto como objeto de recepção crítica, o que se veria seria uma complexa intertextualidade constituída por um texto psicológico, filosófico e histórico.

Essa intertextualidade projeta duas belas imagens: a do filósofo e a do historiador mergulhados, respectivamente, na pesquisa das tradições filosóficas e da história cultural e intelectual do texto psicológico. Mas há, também, escorregos intertextuais do historiador da psicologia, de grandes historiadores, que contribuem para a propagação de idéias freqüentemente desorientadoras sobre o texto de grandes psicólogos (Danziger, 1979; Henle, 1980; Smith, 1986).

O objetivo deste ensaio é sondar a natureza dessa intertextualidade com base em uma breve reflexão sobre história da psicologia apoiada por duas ilustrações históricas: o caso Wilhelm Wundt por Kurt Danziger e o caso Edward C. Tolman por Laurence D. Smith.

1 Endereço: Universidade Federal de São Carlos, Programa de PósGraduação em Filosofia, Via Washington Luís, Km. 235, São Carlos, SP, Brasil 13565-905. E-mail: j.abib@terra.com.br

\section{Intertextualidade do Texto Psicológico}

O objeto da história da psicologia não é como o objeto da física (a natureza), da biologia (a vida) ou da sociologia (a sociedade); é mais parecido com o objeto da história da física, da biologia ou da sociologia. O objeto da história da física, da biologia ou da sociologia é a história do texto da física, da biologia ou da sociologia; e, de modo similar, o objeto da história da psicologia é a história do texto da psicologia.

No âmbito das ciências humanas, por exemplo, na sociologia e na psicologia, a distinção entre objetos da ciência e objetos da história da ciência pode ser colocada em sérios apuros caso se leve em conta, como se leva aqui, a concepção de texto elaborada por Paul Ricoeur. O filósofo francês afirma que texto é discurso escrito. O texto tem três características básicas: não é auto-referencial, não se dirige a uma audiência conhecida e não tem referência denotativa. Isso quer dizer que não expressa a intenção do autor, que qualquer um pode lê-lo e que sua trama de significados é aberta (Abib, 1996a; Ricoeur, 1971) $)^{2}$. Qualquer objeto que tenha tais características é um texto. É o caso, por exemplo, de ações significativas, documentos, monumentos e instituições (Ricoeur, 1971).

2 O que não é um texto? O discurso falado. Naturalmente esse discurso é auto-referencial, se dirige a uma audiência conhecida e tem referência denotativa. 
Pode-se dizer, então, que a psicologia e a sociologia tratam com textos, a primeira, com tramas abertas de significados das ações das pessoas e dos indivíduos, a segunda, com tramas abertas de significados das instituições, dos documentos, monumentos, e das práticas sociais ${ }^{3}$.

O que em primeiro lugar o historiador tem em mãos é um texto de um psicólogo, de um grande psicólogo. E expressa seu principal interesse como historiador com esta indagação: "como este texto nasceu, como cresceu e o que aconteceu com ele?" Trata-se de inquirir a gênese, a carreira e o desfecho de um texto. Quer dizer, ele está interessado no nascimento, desenvolvimento, declínio, abandono e esquecimento do texto. E sua primeira tarefa é dedicar-se à análise estrutural da linguagem do texto. Essa análise, que requer o trato com o texto em sua língua original, consiste basicamente em compreender que um conceito só adquire sentido no contexto de uma teoria, e que, sendo assim, é recomendável sempre perguntar qual é o discurso ou teoria que sustenta a definição de um conceito.

Sem que seja possível apresentar aqui procedimentos detalhados para uma análise desse tipo, é necessário dizer que é com ela que o historiador, não só examina a evolução de um texto, mas também fabrica um arquivo conceitual com o intuito de sondar o pré-texto filosófico do texto: o texto filosófico freqüentemente silencioso que corre por trás do texto psicológico. Essa atividade que habilita o historiador, não só a perceber as transformações significativas de um texto, mas que também o prepara para uma incursão filosófica no texto, requer, para compreensão efetiva de suas consequiências, preparação filosófica do historiador. É com formação filosófica que o historiador avalia se as transformações sofridas por um texto psicológico são solidárias com inflexões filosóficas, e, se forem, é também com ela que aprecia se tais modulações são ou não radicais. E é ainda com o domínio de tradições filosóficas que pode localizar os compromissos filosóficos (lógicos, epistemológicos e metafísicos) da definição teórica de um termo.

Há uma relação de colaboração entre a construção de arquivos conceituais e o domínio de tradições filosóficas, pois apreciações filosóficas arriscam-se ao açodamento e ao erro sem arquivos conceituais, e tais arquivos perdem sua inteligibilidade sem inserções filosóficas apropriadas. Parafraseando uma célebre frase de Kant (1781/1985), o texto psicológico é cego sem seu pré-texto filosófico e o prétexto filosófico é vazio sem o texto psicológico. A história da psicologia é pródiga em exemplos de apreciações vazias do texto psicológico. Para citar a crítica apenas de três: a psicologia de Wundt é um periferalismo (Danziger, 1979), a psicologia da Gestalt é um inatismo (Henle, 1980), Tolman foi influenciado pelo positivismo lógico (Smith, 1986). De outro lado, o texto psicológico pode ser cego se não examina, por exemplo, se uma determinada noção de consciência é ou não atomista, ou se determinada noção de comportamento é ou não mecânica. Ou, ainda, pode ser cego no caso da psicologia da ciência se insinua que a epistemologia genética de Piaget (1956/1978), o comportamentalismo radical de

3 Essa discussão poderia ser estendida às ciências da natureza no contexto da reflexão pós-empirista da ciência representada por obras como as de Kuhn (1970/1975) e Feyerabend (1975/1977).
Skinner (1974) ou o construcionismo social de Gergen (1985, 1989) representam psicologias absolutamente originais da ciência sem antes verificar se não há pré-textos filosóficos com os quais tenham afinidades eletivas.

A intertextualidade do texto do historiador da psicologia não pára por aí. Um texto não é só texto e pré-texto. É também contexto. Atrás de um texto, no fundo, como em uma relação figura-fundo, está o pré-texto. O texto, já por si, como figura, é estrutura. E quando a análise estrutural-conceitual do texto atinge o pré-texto, surge a noção clara de estrutura, na forma de uma relação figura-fundo. Mas uma estrutura se desenvolve e se modifica. Quando um historiador da psicologia pergunta pela gênese, carreira e desfecho de um texto, está fazendo perguntas contextuais sobre uma estrutura certamente peculiar: uma estrutura intertextual. Ocorre que o exame do contexto do texto consiste na inclusão e análise de mais textos. Visando ao seu principal interesse como historiador, faz perguntas contextuais e procura respostas na história intelectual e cultural do texto, em autobiografia e biografias do autor do texto, em documentos (por exemplo, anais e resumos de congressos, participação em associações profissionais), correspondências e testemunhos de colegas e de discípulos e até mesmo na investigação da orientação intelectual de colaboradores. A história intelectual e cultural do texto produz mais textos. E em alguns deles, como no caso de biografias, documentos e testemunhos, o historiador é especialmente zeloso com respeito às questões relacionadas com a origem e legitimidade das fontes. Um zelo que, no entanto, não escapa ao texto. Porque é com outros textos que coloca em dúvida a origem e legitimidade das fontes.

A história intelectual e cultural lida com textos. No fundo, o historiador da psicologia está sempre lidando com textos. A terminologia que está sendo usada aqui - texto, pré-texto, contexto - tem como um de seus objetivos, talvez o principal, destacar a natureza dos textos que são relevantes para caracterizar a intertextualidade do texto psicológico. Nessa intertextualidade, texto refere-se à obra do psicólogo, prétexto à filosofia (especificamente à filosofia da ciência), e contexto às tradições intelectuais e culturais vigentes na época da constituição do texto. No entanto, o pré-texto filosófico é um texto para o filósofo e o contexto intelectual e histórico é um texto para o historiador das idéias e das culturas. O que seria a intertextualidade do texto filosófico ou histórico não é assunto desse ensaio.

Quando um historiador da psicologia pergunta como um texto foi concebido, ele é movido pela crença de que não é suficiente compreender a história interna do texto em sua relação com o pré-texto. Ele sabe que a gênese interna da estrutura texto-pré-texto precisa ser elucidada com outra gênese, a do contexto. História da psicologia é, então, intertextualidade genética ou histórica. Verifica-se, aqui, novamente uma relação de colaboração. Sem a estrutura intertextual, apreciações contextuais são vazias. E sem apreciações contextuais, a estrutura intertextual é cega. Essas duas afirmações não podem, porém, ser tomadas ao pé da letra. Não se pode esquecer que o texto já recebeu esclarecimento do pré-texto e que apreciações contextuais levam adiante esse esclarecimento, às vezes, como será visto no caso de Tolman (Smith, 1986), com resultados surpreendentes, colocando sob suspeita interpretações 
pré-textuais convencionais. Também não se pode esquecer que dificilmente um historiador faz apreciações contextuais de uma estrutura intertextual ignorando-a completamente. Por exemplo, as apreciações contextuais, realizadas por Sigmund Koch e Brian D. Mackenzie, da estrutura intertextual neocomportamentalismo-positivismo lógico foram, de acordo com Smith, em grande parte, equivocadas, mas não se pode dizer que ignoravam tal estrutura. O que ignoravam, como demonstrou cabalmente Smith, foi o contexto intelectual e cultural mais amplo no qual o texto neocomportamentalista foi construído. Esse exemplo é notável para mostrar como a história interna da estrutura texto-pré-texto pode ser colocada em sérios apuros quando outra gênese do texto, o seu contexto, é insuficientemente explorada.

Temos então duas gêneses. A primeira refere-se à estrutura intertextual e a segunda ao contexto dessa estrutura. Pode ser tentador chamar a estrutura intertextual de história interna e o seu contexto de história externa. Essa dualidade é, contudo, equívoca, e seria conveniente desconstruí-la. Trata-se de uma dicotomia com um mérito a ser preservado, mas, fora isso, limita a compreensão da investigação histórica. De um lado, protege o texto de apreciações pré-textuais e contextuais com graus vários de ignorância do texto: as apreciações vazias, ou quase vazias. A noção de história interna desqualifica, com razão, essa estratégia, chamando-a de história externa. Garantida, porém, a investigação da gênese interna da estrutura texto-pré-texto, o contexto não pode ser lido como história externa, porque a gênese contextual é interna àquela estrutura. A dualidade história interna história externa é legítima no que se refere a estratégias preliminares de investigação histórica, mas é equívoca, ao menos no que se refere ao sentido de contexto histórico examinado aqui, para caracterizar a natureza dessa investigação, e por isso é melhor ignorá-la.

Outra possibilidade de distinguir esses dois gêneros de gêneses é inserir a gênese contextual no contexto da descoberta e a gênese da estrutura intertextual no contexto da justificação. Esses contextos tratam com duas questões aparentemente diferentes. No contexto da descoberta investiga-se como uma hipótese, uma teoria ou um discurso, foi concebida. No contexto da justificação investigam-se as razões apresentadas para defender uma hipótese, uma teoria ou um discurso. Um centra-se em "como foi produzido" e o outro no "produto". Pode, pois, parecer um contra-senso falar de gênese no contexto da justificação. É preciso, contudo, frisar que o contexto da justificação não se opõe à gênese interna de uma teoria. A oposição marcada se dá com relação à gênese externa, que incluiria fatores irracionais no metadiscurso científico, comprometendo sua racionalidade: sua constituição lógica, epistemológica e experimental. Até mesmo Popper (1934/1971), que excluiu o contexto da descoberta do metadiscurso científico ${ }^{4}$, já dissera que seu critério de demarcação científica, a refutabilidade lógica de hipóteses e teorias científicas, é uma proposta de convenção ou acordo que ultrapassa toda discussão racional. Com base em suas investigações históricas sobre a ciência, Kuhn (1970/1975) mostrou como concepção de mundo, metafísica,

4 Na perspectiva da filosofia da ciência de Karl Popper, o contexto da descoberta é assunto da psicologia do conhecimento. valores, ideologias e organização institucional participam da constituição da ciência. Tanto Kuhn quanto Feyerabend (1975/1977) questionam a distinção entre contexto da descoberta e contexto da justificação. O contexto da justificação não trata somente com um produto acabado desde seu início, há também uma reconstrução histórica interna que visa à gênese interna. Abre-se, então, com tal reconstrução, um leque de possibilidades investigativas de gêneses internas de mais longo alcance que se encontram no contexto da descoberta. Colocada sob forte suspeita, seria melhor passar por alto a distinção entre contexto da descoberta e contexto da justificação e considerar que a gênese contextual do texto é parte integrante e esclarecedora do texto, até mesmo no caso do texto científico.

A gênese contextual do texto é relevante para compreender, não só a origem e desenvolvimento do texto, mas também o seu destino. Revoluções na psicologia freqüentemente atingem o contexto de constituição do texto. É ilusão pensar que um texto é abandonado por decisões estritamente racionais. Por exemplo, Danziger (1979) mostra que a psicologia de Wundt foi derrotada no campo da metafísica ou da filosofia da ciência - desde que se entenda que filosofia da ciência envolve epistemologia e metafísica (Abib, 1993) -, o que só pode ser apreciado no contexto intelectual e cultural alemão da obra do fundador do projeto da psicologia científica. Isso pode parecer surpreendente na medida em que o discurso usual sobre o abandono de teorias científicas gira em torno da não confirmação ou da refutabilidade lógica de tais teorias. Herdamos do positivismo lógico um critério de demarcação científica que exclui a metafísica do âmbito da ciência (Hahn, Neurath \& Carnap, 1929/1986). E o racionalismo crítico de Popper (1934/1071) legou-nos um critério de demarcação científica que exclui da ciência enunciados logicamente não refutáveis. Longe da metafísica, ciência refere-se a hipóteses logicamente refutáveis e a testes experimentais. Tais testes podem efetivamente refutar tais hipóteses, que devem, então, ser reformuladas. Se resistirem à refutação, são confirmadas; apenas provisoriamente, contudo, até que sejam refutadas por novos testes. Bem antes de Kuhn (1970/1975), Burtt (1932/1983) já mostrara que a metafísica do mecanicismo atravessava toda a ciência moderna. A época não era propícia à tese de Burtt, pois o positivismo lógico já começava a dominar o metadiscurso da ciência, afirmando que proposições metafísicas são desprovidas de sentido lógico e empírico. $\mathrm{Na}$ verdade, diziam que são apenas expressões de sentimento, cujo campo apropriado é, no entanto, a arte, a música e a poesia lírica, por exemplo, e não a ciência (Hahn \& cols., 1929/1986 ). É razoável acautelar-se contra a tese de uma decisão estritamente racional, não só com relação a revoluções psicológicas, mas também com relação a revoluções científicas (Danziger, 1979; Kuhn, 1970/1975) ${ }^{5}$. No mínimo, a metafísica tem um papel tão importante quanto decisões racionais. Por exemplo, o comportamentalismo mecanicista de Clark Hull foi criticado pelo formalismo lógico do modelo hipotético-dedutivo (Skinner, 1969; Tolman, 1959/1977). Mas, a ascensão da crítica à metafísica do mecanicismo não exerceu nenhum efeito sobre essa versão de comportamentalismo?

5 Embora não pareça, essa frase não insinua que a psicologia não é ciência. 


\section{O Caso Wundt por Danziger}

O impressionante exame que Danziger (1979) faz da rejeição da psicologia de Wundt é esclarecedor. Em seu discurso, Danziger demonstra de forma clara e incisiva porque o livro Análise das sensações de Ernst Mach bem que poderia ser recomendado como o primeiro texto em um curso de história da psicologia cujo objetivo fosse o de compreender revoluções, reformas e retomadas na psicologia. Danziger argumenta que há uma revolução bem ali onde não parece haver: na passagem da psicologia centralista de Wundt para a psicologia periferalista de Edward B. Titchener. E que há uma reforma bem ali onde parece haver uma revolução: na passagem da psicologia periferalista de Titchener para o comportamentalismo. No primeiro caso, Danziger polemiza com o renomado historiador da psicologia experimental Edwing G. Boring. No segundo, pode-se dizer que se dirige a todos aqueles que vêem no comportamentalismo uma descontinuidade discursiva com respeito à psicologia periferalista de Titchener ${ }^{6}$.

O livro de Mach é um texto de grande repercussão sobre filosofia positivista da ciência e foi fundamental - com a filosofia positivista de Richard Avenarius - para a concepção de psicologia abraçada por Oswald Külpe, Titchener e Hermann Ebbinghaus (Danziger, 1979). Análise das sensações é um repúdio a concepções metafísicas na ciência ${ }^{7}$. A crítica a Wundt começa com a obra Esboço de psicologia, de seu discípulo e assistente Külpe, publicada em 1893. A crítica tem alvo certo: o conceito de causalidade psíquica. Causalidade psíquica refere-se à experiência da conexão de processos psíquicos e ao significado e valor dessa experiência. Uma idéia pode depender de outra idéia ou emoção, uma emoção pode depender de outra emoção ou idéia, e a experiência de uma idéia ou emoção tem significado e valor. Causalidade psíquica não pode ser derivada da causalidade física ou da causalidade fisiológica. Causalidade psíquica é um fenômeno da experiência imediata: depende do fator subjetivo, ou do sujeito da experiência (Wundt, 1896/1922). Causalidade física é um fenômeno da experiência mediata: depende da abstração do fator subjetivo, ou do sujeito da experiência (Wundt) - por isso, é uma inferência ou uma construção conceitual. De acordo com o princípio de causalidade psíquica, um fenômeno psicológico deve ser explicado com causas psicológicas.

Danziger (1979) comenta que o conceito de causalidade psíquica de Wundt não tinha capacidade heurística e permaneceu como abstração vazia. Essa falta de conteúdo teria contribuído para o sucesso da crítica dos psicólogos machianos. Esse limite heurístico da psicologia de Wundt não compromete necessariamente a idéia básica do conceito de causalidade psíquica. Embora não reconheça influências aparentes de Wundt, Danziger cita a noção de espaço vital de Kurt Lewin e de determinismo psíquico de Sigmund Freud como expressões posteriores do conceito de causalidade psíquica. Mais importante, todavia, é a delimitação da questão central que envolveu a crítica de Külpe, Titchener e Ebbinghaus a Wundt.

6 De qualquer modo, Danziger recorre a Boring para afirmar que o periferalismo de Titchener é uma forma de comportamentalismo.

7 Para tornar explícito seu vínculo com Mach, os positivistas lógicos organizaram-se como membros da Sociedade Ernst Mach (Hahn, Neurath $\&$ Carnap, 1929/1986).
Para os psicólogos machianos, o conceito de causalidade psíquica é metafísico. Danziger (1979) comenta que Külpe fez uma distinção entre o indivíduo psíquico e o indivíduo corpóreo (chamado mais tarde de organismo por Ebbinghaus) e que abandonou a primeira noção, o que equivalia a refutar o conceito de causalidade psíquica. O conceito de indivíduo psíquico implicava uma agência central - um agente ou homúnculo - responsável pelos fenômenos da experiência imediata. A noção de que ciência é observação, descrição e formulação de relações funcionais - traços fundamentais da filosofia positivista da ciência de Mach (1885/1925) - tornava inaceitáveis as noções wundtianas de agência central e causalidade psíquica. Nos passos do filósofo inglês David Hume, Mach argumentava que o self ou o Eu não passa de um feixe de sensações. A experiência que temos é de sensações. Não temos nenhuma experiência de uma agência central - uma ficção explanatória, portanto. Eis a frase que os psicólogos machianos escolheram para acertar o coração da psicologia de Wundt: é metafísica!

A controvérsia entre Wundt e os psicólogos machianos acerca da noção de indivíduo psíquico reflete discordâncias no âmbito da filosofia da ciência (Danziger, 1979). A filosofia da ciência machiana é solidária com o reducionismo fisicalista que pode ser verificado na noção de hierarquia das ciências. Quanto mais abstratas e gerais as leis de uma ciência, mais próxima da base dessa hierarquia estará essa ciência. A física ocuparia essa posição e em seguida viriam biologia, psicologia e sociologia. Uma ciência mais básica explicaria uma menos básica. Por exemplo, a biologia explicaria a psicologia que, por sua vez, explicaria a sociologia. A recíproca não é verdadeira: a sociologia não explicaria a psicologia e essa não explicaria a biologia. Em última análise, a psicologia seria explicada pela física. Já a filosofia da ciência wundtiana é solidária com a irredutibilidade da psicologia à física, o que equivale a dizer, da causalidade psíquica à causalidade física ou do indivíduo psíquico ao indivíduo corpóreo. Wundt defendia a dualidade da ciência ou a irredutibilidade dos conceitos das ciências do espírito (Geisteswissenschaften) aos conceitos das ciências da natureza (Naturwissenschaften). $\mathrm{O}$ psicólogo alemão reconhecia e aceitava a orientação hegeliana sobre as ciências, cuja origem encontra-se na distinção feita pelo filósofo alemão entre filosofia da natureza e do espírito. A diferenciação entre causalidade psíquica e física é coerente com essa concepção dual da ciência, enquanto que a concepção hierárquica da ciência apóia a noção de unidade da ciência, a idéia de que todas as ciências podem ser explicadas em termos de causalidade física.

A filosofia da ciência dos psicólogos machianos é um reducionismo fisicalista e a filosofia wundtiana da ciência é claramente anti-reducionista e antifisicalista. Orientados pelo reducionismo fisicalista e definindo psicologia como estudo da experiência do organismo biológico, os psicólogos machianos chegaram à sensação como o fenômeno fisiológico capaz de explicar os fenômenos psicológicos (Danziger, 1979). Por exemplo, Titchener chegou a defender que os sentimentos (feelings) de excitação-depressão, tensão-relaxamento e prazer e dor não passam de sensações orgânicas ${ }^{8}$.

8 Outros psicólogos machianos achavam que prazer e dor contêm um resíduo ineliminável, não podendo, portanto, ser interpretados como 
A explicação reducionista de fenômenos psicológicos, como nesse caso em que feelings são reduzidos a sensações orgânicas, atendia a outra característica da filosofia machiana da ciência: o princípio de economia conceitual. Sensações - ou, no máximo, sensações e afetividade, para os psicólogos machianos que acreditavam na irredutibilidade dos sentimentos de prazer e dor a sensações - são suficientes para explicar todos os processos psicológicos, dos mais simples aos mais complexos. Dessa perspectiva reducionista fisicalista, o conceito wundtiano de causalidade psíquica (uma força mental) era antieconômico. Danziger comenta que foi então a vez de Wundt acusar a presença de metafísica na filosofia positivista de Mach: pois, afinal, afirmar que a natureza prefere os meios mais simples, não é transformar o princípio de economia conceitual em uma crença metafísica?

Esse sensacionismo positivista foi elevado explicitamente à condição de metafísica por Titchener quando distinguiu entre experiência atual e a experiência real (Danziger, 1979). A experiência atual envolve sensações, significado, valores e propósitos. A experiência real é pura, só envolve sensações. Consequientemente, é necessário abstrair da experiência atual, significados, valores e propósitos para adentrar a experiência pura. Que é, então, elevada à condição de uma construção ou inferência. Como Danziger nota, Wundt diria que, concebida desse modo, experiência pura seria experiência mediata e não poderia ser objeto de estudo da psicologia. Vale notar que em 1929, Wolfgang Köhler fez uma crítica similar à noção de experiência pura quando criticou a psicologia introspectiva. Köhler também apontou semelhanças, mais do que ocasionais, entre a noção de experiência pura e a definição objetiva de comportamento do comportamentalismo - uma definição que visava expurgar referências subjetivas, como propósito, significado, e similares. As semelhanças entre o periferalismo de Titchener e o comportamentalismo seriam verificáveis em neocomportamentalistas como Tolman, Hull e Skinner (Danziger, 1979; Leahey, 1981). Thomas H. Leahey chega a afirmar que Skinner é o duplo de Titchener!

\section{Escorregos e Omissões Intertextuais}

Há na passagem da psicologia centralista de Wundt para a psicologia periferalista de Titchener e de outros psicólogos machianos uma revolução, ou uma vitória no campo da metafísica, e mudança radical do projeto da psicologia, onde não parecia haver (Danziger, 1979). E há na passagem da psicologia periferalista de Titchener para o comportamentalismo uma reforma onde parecia haver uma revolução (Danziger). Köhler (1929/1970) critica a metafísica do sensacionismo positivista e a metafísica do comportamentalismo nos capítulos iniciais de seu livro e somente depois apresenta o projeto da psicologia da Gestalt. É no campo da metafísica (é a lição de Köhler) que as psicologias apoiadas por essas metafísicas tinham que ser enfrentadas, pois, afinal, a psicologia da Gestalt é antipositivista (Koffka, 1935/s.d.). Reforma, diz Danziger, diferentemente de revolução, muda os meios sem mudar os fins. O comportamentalismo seria uma reforma do projeto

meras sensações orgânicas. E isso porque prazer e dor pareciam ser um complexo central com capacidade de selecionar e direcionar processos psicológicos. da psicologia com preservação dos fins do sensacionismo positivista: o positivismo machiano. Enfim, Wundt teria sido derrotado no enfrentamento com a metafísica positivista periferalista de Külpe, Titchener e Ebbinghaus, reformada e fortalecida pelo advento do comportamentalismo e seus desdobramentos neocomportamentalistas.

Essa história sobre Wundt é admirável para quem está acostumado com o livro de Boring (1950) sobre história da psicologia experimental e mesmo com outros textos mais recentes - como os de Sahakian (1975/1987), Schultz e Schultz (1969/s.d.), Robinson (1986) - sobre história da psicologia e mostra bem a pertinência do título de um texto de Blumenthal (1979) sobre Wundt: O pai fundador que nunca conhecemos. E é inesperada também com respeito ao caso do comportamentalismo, até porque, como Danziger (1979) reconhece, tradicionalmente diz-se que os vínculos do comportamentalismo são com o funcionalismo. Mais imprevisível talvez é verificar como competentes historiadores da psicologia incorrem em erros parecidos com aqueles que denunciam em seus colegas. A crítica de Danziger a Boring pertence ao discurso histórico mais recente sobre Wundt, um discurso que inclui uma plêiade de historiadores conhecedores do texto de Wundt e que são unânimes em sua crítica à leitura de Boring e de outros que praticamente o repetem. Mas alguns deles cometem um erro similar quando se referem ao comportamentalismo. A primeira coisa que salta aos olhos é a parca referência à literatura dos psicólogos comportamentalistas. Por exemplo, Danziger cita apenas um texto de Hull, um trecho autobiográfico de Skinner, e não faz nenhuma referência a Tolman! E Leahey (1981) cita dois livros e um ensaio de Skinner e dois autores que se tornaram canônicos na crítica ao comportamentalismo: Koch e Mackenzie (esse último citado também por Danziger). Não deixa enfim de ser curioso notar que nem Danziger nem Leahey atribuam créditos de suas teses da relação do comportamentalismo com o periferalismo da psicologia de Titchener à análise seminal de Köhler em 1929. Evidentemente as referências de Danziger e Leahey são insuficientes para avaliar os compromissos metafísicos ou as filosofias da ciência do comportamentalismo.

A avaliação convincente das filosofias da ciência e das metafísicas do comportamentalismo só viria mais tarde (Chiesa, 1994; Morris, 1988; Smith, 1986; Zuriff, 1985). As alianças metafísicas fundamentais do comportamentalismo são com o pragmatismo filosófico (Morris, Smith, Zuriff) e com o organicismo (Chiesa). De especial interesse para a presente discussão é a intrigante análise desenvolvida por Smith acerca das relações do neocomportamentalismo com o positivismo lógico. O objetivo de Smith é avaliar se a aliança do neocomportamentalismo com o positivismo lógico é tão estreita e fechada como tem sido divulgada por historiadores como Koch e Mackenzie. Smith demonstra que quando similaridades conceituais dão o mote para reconstruções racionais, freqüentemente resvalam na falácia da influência. Mostra com notável habilidade que semelhanças não significam de modo algum influência, e que a tese tradicional, defendida por Koch e Mackenzie, de que o neocomportamentalismo foi influenciado pelo positivismo lógico, baseia-se em reconstruções racionais que pecam em dois sentidos. Em primeiro lugar guiam-se por semelhanças mal fundamentadas - por exemplo, Smith mostra que 
nenhum dos neocomportamentalistas que examina tinham maior apreço pela diretriz lógica do positivismo lógico - e, em segundo lugar, passam ao largo de contextos intelectuais e culturais que, examinados cronologicamente com relação à origem e desenvolvimento do texto neocomportamentalista, respondem melhor por semelhanças e influências. A pesquisa de Smith é um excelente exemplo da tese de que o contexto é interno ao texto. O caso mais notável estudado por Smith é o de Tolman.

\section{O Caso Tolman por Smith}

Smith (1986) argumenta que o contexto relevante para esclarecer a constituição e desenvolvimento do texto de Tolman envolve a filosofia do neo-realismo norte-americano, o pragmatismo filosófico (especialmente o pragmatismo contextualista de Stephen C. Pepper), a psicologia da Gestalt, o funcionalismo probabilista de Egon Brunswik e a psicologia freudiana. Smith escreve uma convincente história dessas relações (não examina a relação com Freud), e o que se faz aqui é um breve resumo da formação da tensão entre o operacionismo e as variáveis intervenientes de Tolman (1932) com o propósito de mostrar em que sentido as afinidades de Tolman com a filosofia do neo-realismo norte-americano e com a psicologia da Gestalt funcionam como contra-exemplo para a tão divulgada tese da influência do positivismo lógico na obra desse neocomportamentalista. No operacionismo de Tolman, variáveis intervenientes, como intenção e cognição, podem ser observadas diretamente porque se referem a propriedades que se apresentam no comportamento. Esse operacionismo que afirma a imanência da intenção e da cognição no comportamento é de diretriz neo-realista. O neo-realismo afirma que a mente está presente no comportamento e que, sendo assim, pode ser observada diretamente e conhecida do mesmo modo como o são as coisas e objetos do mundo natural. O neo-realismo naturaliza a mente. Smith comenta que em 1925 Tolman também afirmou que intenção e cognição são determinantes do comportamento. Esses conceitos se tornaram então equívocos. De um lado, estavam presentes no comportamento e, de outro lado, explicavam o comportamento. Tolman começava a se defrontar com um problema que foi determinante para a ruína do neo-realismo. Os neo-realistas afirmavam que outras mentes são totalmente públicas e diretamente observáveis e que nada do que é mental é privado, ou, enfim, que o comportamento do outro serve para um observador ler sua mente e não para inferi-la. Essa tese foi fortemente criticada, especialmente porque parecia que havia casos em que a mente não podia ser lida diretamente no comportamento. Smith diz que Ralph B. Perry e Edwin B. Holt - professores de Tolman em Harvard e membros do grupo que fundou o neo-realismo - recorreram então a explicações neurofisiológicas para preservar a investigação naturalista e objetiva da mente. Tolman não tinha apreço por esse tipo de explicação, que já tinha conduzido John B. Watson ao que ele, Tolman, depreciativamente chamou de psicologia das contrações musculares. Essas dificuldades, ao lado das críticas do realismo crítico ao neo-realismo, derrotaram esse último, e Perry e Holt terminaram também por abandoná-lo.
Smith (1986) revela também como o contexto da psicologia da Gestalt contribuiu para formar o conceito de variável interveniente. $\mathrm{O}$ grande comentador do behaviorismo descreve como o conceito de signo-gestalt foi desenvolvido nos anos que precederam a publicação do clássico de Tolman em 1932. Nesse ano Tolman escreveu que expectativa refere-se a um signo-gestalt. Basicamente um signo-gestalt resume-se em uma relação de três termos: uma deixa (um objeto-signo), uma meta (um objeto-significado) e um campo de rotas comportamentais (relaçõesmeios-fim) que conduzem o organismo do objeto-signo ao objeto-significado. A expectativa refere-se à espera desse tipo de relação complexa que envolve um campo de relações de ações, signos e significados, e que caracteriza o ato psicológico propriamente dito, diferenciando-o de simples movimentos destituídos de significados. À expectativa assim caracterizada, Tolman chamou de determinante cognitivo imanente do comportamento. Constata-se mais uma vez, com as noções de imanência e de determinante, a tensão entre o operacionismo neo-realista de Tolman e a variável interveniente. Só que, agora, essa ambigüidade ocorre em outro contexto, que é o da psicologia da Gestalt.

Smith (1986) diz que essa equivocidade acompanhou Tolman por dez anos, de 1925 a 1935, e que só foi resolvida depois de sua viagem a Viena, entre 1933 e 1934 . O problema que Tolman levava a Viena era este: como definir de modo operacional e objetivo fenômenos mentais, como intenção e cognição, e ao mesmo tempo afirmar que são inferidos do comportamento? Tolman resolveria esse problema ao interpretar o conceito de variável interveniente como construto hipotético, à maneira de Rudolf Carnap ${ }^{9}$. Segundo Smith, Tolman sofisticaria seu operacionismo em virtude de suas relações com o positivismo lógico, mas a contribuição dessa filosofia teria sido de caráter mais corroborativo do que formativo. É isto o que Smith escreve: “(...) operacionismo - o ponto preciso de contato intelectual entre Tolman e os positivistas lógicos - foi desenvolvido por Tolman antes de seu conhecimento do positivismo lógico (...) e foi um desenvolvimento natural de suas pressuposições metafísicas neo-realistas" (p. 87).

Investigando contextos constitutivos do texto comportamentalista, Smith (1986) mina a interpretação tradicional da aliança do neocomportamentalismo com o positivismo lógico, formulada por Koch e Mackenzie e incansavelmente repetida em manuais de história da psicologia ${ }^{10}$. Uma das conclusões mais memoráveis de Smith, e que infelizmente não há espaço para ser examinada aqui, é que as psicologias pragmatistas da ciência de Tolman e Skinner retratam uma concepção da ciência em franca oposição à do positivismo lógico ${ }^{11}$.

9 O exame dessa solução foge aos objetivos deste ensaio. Sugere-se consultar Abib (1997) para o exame de alguns aspectos dessa solução.

10 Smith não perde a oportunidade de fazer uma crítica ao manual História da psicologia de Leahey precisamente nesse ponto.

11 Zuriff (1985) já havia defendido que o pragmatismo é a filosofia da ciência do comportamentalismo. Mais tarde, Morris (1988) argumentou que o comportamentalismo radical é solidário com o contextualismo pragmático de Pepper, e Chiesa (1994) fez uma leitura do texto de Skinner na perspectiva de um organicismo ou de um relacionismo próximo às teses organicistas de Fritjof Capra. 


\section{Danziger e Boring sobre Tolman}

Afinal, qual é a afirmação de Danziger (1979) sobre Tolman, e qual é sua fonte, se não cita um texto sequer do neocomportamentalista? Em suas palavras: "Tanto a consciência quanto a inconsciência são inferidas', afirma Boring, relegando assim a consciência à condição de uma variável interveniente, que é exatamente a posição que lhe é atribuída no neocomportamentalismo de E. C. Tolman" (p. 223). Danziger faz essa afirmação quando está demonstrando o caráter metafísico do sensacionismo de Titchener e a defesa do psicólogo periferalista de que a realidade sensorial é inferida. Seria no contexto dessa metafísica machiana que a consciência é uma variável interveniente. Mas, essa afirmação é, no mínimo, uma simplificação histórica, pois variável interveniente no texto de Tolman - seja intenção, cognição, expectativa, consciência -, relaciona-se com outros contextos discursivos, como o problema do conhecimento de outras mentes no neo-realismo e a explicação da atividade psicológica em termos de signo-gestalt. E não é só isso: Tolman pode ser interpretado como um psicólogo dinamicista (Boring, 1950). Em seu capítulo sobre psicologia dinâmica, Boring arrola um grande número de psicólogos, como, por exemplo, Jean Martin Charcot, Pierre Janet, Freud, Lewin, William McDougall, Holt e Tolman. Boring comenta que as noções de idéia ativa e de motivação são básicas na psicologia dinâmica: idéia ativa é força, e força é tensão, que é liberada na ação. A variável interveniente de Tolman é uma força: a expectativa determina a ação. Quando Smith (1986) afirma que a psicologia freudiana representa um dos contextos para elucidar o texto de Tolman, entenda-se por isso, ao menos, o contexto da psicologia dinâmica e o interesse que Holt tinha na psicanálise, expresso, por exemplo, em seu livro $O$ desejo freudiano e seu lugar na ética ${ }^{12}$. Danziger, curiosamente, não cita esse texto de Boring ao se referir a Tolman. E, seguramente, trata-se de um comentário importante de Boring que poderia contribuir para mutatis mutandis aproximar as psicologias dinâmicas de Wundt e Tolman no que se refere às noções de idéia ativa e motivação.

\section{Conclusão}

Danziger (1979) viu uma revolução onde tradicionalmente se vê uma reforma e viu uma reforma onde tradicionalmente se vê uma revolução. Revolução psicológica significa descontinuidade discursiva no âmbito da metafísica e da epistemologia (Abib, 1993, 1996b; Danziger). Uma descontinuidade assim teria ocorrido na passagem da psicologia de Wundt para a psicologia de Külpe, Titchener e Ebbinhaus, mas não na passagem do periferalismo de Titchener para o comportamentalismo.

É inegável que o positivismo - não tanto, nem somente, o positivismo lógico - é parte integrante da filosofia da ciência do comportamentalismo, pois o "pragmatismo comportamentalista está entrelaçado na tradição intelectual mais ampla do positivismo, especialmente o empiriocriticismo de Mach e Avenarius" (Zuriff, 1985, p. 261). E é bem conhecida a

12 Como Smith, Boring também destaca a influência de Holt sobre Tolman. declaração de Skinner (1931/1999) de que o método que usou em sua pesquisa histórica do reflexo segue a orientação metodológica do criticismo de Mach - que, segundo ele, teria sido formulada melhor por Jules Henri Poincaré e excelentemente aplicada por Percy Williams Bridgman. Porém, no caso de Skinner, Smith (1986) e Morris (1988) frisaram muito mais o pragmatismo do que o positivismo. E Chiesa (1994) sublinhou o organicismo ou o relacionismo ${ }^{13}$. O caso Tolman, sucintamente apresentado, serve, não só como contra-exemplo à tese tradicional da aliança do neocomportamentalismo com o positivismo lógico, mas também para frisar um contexto não positivista de seu neocomportamentalismo: o contexto da psicologia da Gestalt. Com efeito, eis o que um expoente da psicologia da Gestalt escreveu sobre seu livro Princípios de psicologia da Gestalt: "Se algum espírito polêmico existe neste livro, ele não é dirigido contra pessoas, mas contra uma poderosa força cultural em nossa presente civilização, para a qual escolhi o nome de positivismo" (Koffka, 1935/s.d., p. 693).

A investigação histórica de textos psicológicos revela a presença de várias filosofias da ciência correndo por baixo do texto, no pré-texto. O recorte filosófico da leitura é interessado: baseia-se em um exame do sentido da obra no seu entrelaçamento com as crenças metafísicas e epistemológicas do intérprete. Qual é o interesse, então, de ler todo o texto comportamentalista como um positivismo machiano? Como se pode perguntar também: se Danziger (1979) estiver certo com respeito a Wundt e à sua crítica a Boring, e parece que está $^{14}$, qual terá sido o interesse de Boring em ler o texto wundtiano na versão titcheneriana ${ }^{15}$ ?

A leitura que Danziger (1979) faz do comportamentalismo é, no mínimo, limitada. Não segue, no caso do comportamentalismo, o padrão da investigação histórica: o exame dos contextos do texto. Sendo assim, não poderia sua crítica à leitura que Boring (1950) fez de Wundt ser mutatis mutandis auto-aplicável? Para um historiador do calibre de Danziger, talvez isto seja o mais imprevisto: a estranha ausência em seu discurso do texto neocomportamentalista. Não terá lido o primeiro capítulo do clássico de Tolman (1932) no qual o neocomportamentalista declara seus vínculos com os neorealistas Perry e Holt? Ou o último, no qual argumenta que seu sistema é também um gestaltismo?

Um breve exame de alguns textos de historiadores da psicologia demonstra que investigar a história da psicologia envolve uma complexa intertextualidade. Trata-se da intertextualidade do texto psicológico com o pré-texto filosófico e com o contexto histórico cultural e intelectual vigente na

13 Smith também faz uma ampla defesa do pragmatismo de Tolman.

14 Essa apreciação não significa dizer que Boring (1950) ignorava todo e qualquer aspecto dinâmico da psicologia de Wundt.

15 Pode-se dizer que Boring se equivocou ao fazer essa leitura (Abib, 1996b). Pode-se dizer, também, que havia o interesse, provavelmente implícito, do historiador da psicologia experimental em conferir legitimidade científica à obra de Titchener fincando, para isso, seus alicerces na obra do pai fundador do projeto da psicologia científica. A redução indiscriminada do texto comportamentalista à leitura machiana pode ser vista como uma tentativa de desferir um golpe mortal no comportamentalismo, e de resto na psicologia periferalista, com o propósito não declarado de favorecer a psicologia centralista, especialmente a noção de causalidade psíquica. 
época da constituição do texto. Os trabalhos de Danziger (1979) e de Smith (1986) são emblemáticos para justificar a afirmação de que o contexto é interno ao texto, e que, portanto, não cabe desqualificá-lo com nomes supostamente infamantes como história externa e contexto da descoberta. Em última análise, é o contexto, ou a história, que explica a complexa estrutura texto-pré-texto.

A reconstrução racional ou a história que é contada a partir de semelhanças verificadas entre o texto e o pré-texto pode ser um excelente guia para a investigação histórica de contextos do texto. Porém, esse procedimento tem seus perigos, como o de propor similaridades com base em exames insuficientes do texto e do pré-texto. Essa situação torna-se pior quando se faz apreciações sobre relações de semelhança apenas sob a ótica dos textos de outros historiadores. Mas, pode o historiador ignorar suas próprias lições como as de estudar seriamente o texto e estabelecer com rigor semelhanças conceituais com o pré-texto para que valha a pena investir na complexa pesquisa histórica de contextos?

\section{Referências}

Abib, J. A. D. (1993). “A psicologia é ciência?” O que é ciência? Psicologia: Teoria e Pesquisa, 9(3), 451-464.

Abib, J. A. D. (1996a). Epistemologia, transdisciplinaridade e método. Psicologia: Teoria e Pesquisa, 12(3), 219-229.

Abib, J. A. D. (1996b). Revoluções psicológicas: Um retorno a Wilhelm Wundt, William James e outros clássicos. Cadernos de História e Filosofia da Ciência, 6(1), 107-143.

Abib, J. A. D. (1997). Teorias do comportamento e subjetividade na psicologia. São Carlos: Editora da UFSCar.

Blumenthal, A. L. (1979). The founding father we never knew. Contemporary Psyhology, 24(7), 548-550.

Boring, E. G. (1950). A history of experimental psychology. New York: Appleton-Century-Crofts.

Burtt, E. A. (1983). As bases metafísicas da ciência moderna (J. V. Filho \& O. A. Henriques, Trads.). Brasília: Editora Universidade de Brasília. (Trabalho original publicado em 1932)

Chiesa, M. (1994). Radical behaviorism: The philosophy and the science. Boston: Authors Cooperative.

Danziger, K. (1979). The positivist repudiation of Wundt. Journal of the History of the Behavioral Sciences, 15, 205-230.

Feyerabend, P. (1977). Contra o método (O. S. da Mota \& L. Hegenberg, Trads.). Rio de Janeiro: Livraria Francisco Alves. (Trabalho original publicado em 1975)

Gergen, K. (1985). The social constructionist movement in modern psychology. American Psychologist, 40(3), 266-275.

Gergen, K. (1989). Social psychology and the wrong revolution. European Journal of Social Psychology, 19, 463-484.

Hahn, H., Neurath, O. \& Carnap, R. (1986). A concepção científica do mundo - O Círculo de Viena: Dedicado a Moritz Schlick (F. P. de A. Fleck, Trad.). Cadernos de História e Filosofia da Ciência, 10, 5-20. (Trabalho original publicado em 1929).

Henle, M. (1980). The influence of Gestalt psychology in America. Em R. W. Rieber \& K. Salzinger (Orgs.), Psychology: Theoretical-historical perspectives (pp. 177-190). New York: Academic Press.

Kant, I. (1985). Crítica da razão pura (M. P. dos Santos \& A. F. Morujão, Trads.). Lisboa: Fundação Calouste Gulbenkian. (Originalmente publicado em 1781).
Koffka, K. (s.d.). Princípios de psicologia da Gestalt (A. Cabral, Trad.). São Paulo: Cultrix (Trabalho original publicado em 1935).

Köhler, W. (1970). Gestalt psychology: An introduction to new concepts in modern psychology. New York: Liveright (Originalmente publicado em 1929).

Kuhn, T. (1975). A estrutura das revoluções científicas (B. V. Boeira e N. Boeira, Trads). São Paulo: Perspectiva. (Trabalho original publicado em 1970)

Leahey, T. H. (1981). The mistaken mirror: On Wundt's and Titchener's psychologies. Journal of the History of the Behavioral Sciences, 17, 273-282.

Mach, E. (1925). Análisis de las sensaciones (E. O. y Maury, Trad.). Madrid: Daniel Jorro (Originalmente publicado em 1885).

Morris, E. K. (1988). Contextualism: The world view of behavior analysis. Journal of Experimental Child Psychology, 46, 289323.

Piaget, J. (1978). Psicologia e epistemologia: Por uma teoria do conhecimento (A. Cretella, Trad.). Rio de Janeiro: Forense Universitária. (Trabalho original publicado em 1957)

Popper, K. (1971). La lógica de la investigación científica (V. S. De Zavala, Trad.). Madrid: Editorial Tecnos. (Trabalho original publicado em 1934)

Ricoeur, P. (1971). The model of the text: Meaningful action considered as a text. Social Research, 38, 529-562.

Robinson, D. N. (1986). An intellectual history of psychology. Wisconsin: The University of Wisconsin Press.

Sahakian, W. S. (1987). Historia y sistemas de la psicología (A. S. Torres, Trad.). Madrid: Editorial Tecnos (Trabalho original publicado em 1975).

Schultz, D. P. \& Schultz, S. E. (s.d.). História da psicologia moderna (A. U. Sobral \& M. S. Gonçalves, Trads.). São Paulo: Cultrix. (Trabalho original publicado em 1969)

Skinner, B. F. (1969). Contingencies of reinforcement: A theoretical analysis. New York: Appleton-Century-Crofts.

Skinner, B. F. (1974). About behaviorism. New York: Alfred A. Knopf.

Skinner, B. F. (1999). The concept of the reflex in the description of behavior. Em B. F. Skinner (Org.), Cumulative record (pp. 475503). Massachusetts: Copley Publishing Group. (Originalmente publicado em 1931).

Smith, L. D. (1986). Behaviorism and logical positivism: A reassessment of the alliance. Stanford: Stanford University Press.

Tolman, E. G. (1932). Purposive behavior in animals and men. New York: The Century.

Tolman, E. G. (1977). Principios de conducta intencional (S. de Schcolnik, Trad.). Buenos Aires: Ediciones Nueva Visión (Trabalho original publicado em 1959)

Wundt, W. (1922). Grundriss der psychologie. Leipzig: Alfred Kröner Verlag (Originalmente publicado em 1896).

Zuriff, G. E. (1985). Behaviorism: A conceptual reconstruction. New York: Columbia University Press.

Recebido em 12.05.2004

Primeira decisão editorial em 25.10.2004

Versão final em 10.12.2004

Aceito em 28.02.2005 